\title{
Conjoineted Twins Sonography
}

\author{
Ahmad Soltani Shirazi ${ }^{1, *}$ \\ ${ }^{1}$ Ahwaz Jundishapour Medical, Khuzestan, Iran \\ "Corresponding author: Ahmad Soltani Shirazi, Ahwaz Jundishapour Medical, Khuzestan, Iran. E-mail: dra.soltanishirazi@gmail.com
}

Received 2016 December 21; Accepted 2017 February 08.

\begin{abstract}
One of the complications of Twinning of mono chorionic mono amniotic gestations is conjointed Twins. Structural congenital malformations occur in $5 \%$ to $7 \%$ of twin gestations versus only $3 \%$ of singleton births. Most defects occurring in only one of the twin fetuses. Occasional anomalies such as omphalocele sincenomalia heart defect one reported in both concordance. The structural defect commonly associated with monozygotic twins included conjoined twins: extrophy of bladder, vertebral defect .trachea esophageal fistula with esophageal atresia anomalies (VATER complex) anencephaly. Congenital heart defect and holopro cencephaly. The incidence of con joined twins is approximately 1 of $5000070 \%-75 \%$ are female. The classification are 1 ) thoraco pagus: jointed at the thorax. They may share the chest and upper abdominal organs. This is the most common type (70\%). 2) Xiophopagus on omphalopagus: jointed by the anterior abdominal wall down to umbilicus 3) pygopagus: jointed by the sacrum and coccyx lying back to back. 4) Ischiopagus: jointed at the ischium or sacrum lying side by side. 5) Craniopagus: jointed at the cranium lying at right angles each other. The sonographic role of management of conjointed twins is to make diagnosis and detect associated anomaly and the extent of joining of twins and map out the defect and determine the likelihood of post natal viability.
\end{abstract}

This is an abstract presented in the 33rd Iranian congress of radiology (ICR) and the 15th congress of Iranian radiographic science association (IRSA). 